\title{
The importance of timing in surgical treatment of unruptured symptomatic aneurysm of abdominal aorta
}

\author{
Pasternak J, Nikolic D, Popovic V, Vucaj-Cirilovic V \\ Clinic of Vascular and Endovascular Surgery, Clinical Centre Vojvodine, Novi Sad, Serbia. paster@neobee.net
}

\begin{abstract}
Aim of study: Aim of this study is to define an entity of unruptured symptomatic AAA, to examine the influence of timing of the surgical treatment and to analyze the results of the treatment of unruptured symptomatic AAA in acute expansion.

Materials and method: The study is designed as retrospective analysis of 390 operatively treated patients in the last five years at the Clinics of Vascular Surgery in Novi Sad. All patients were grouped into four categories: elective operative surgical treatment, surgical treatment 24 hours after the admission through the Department of Urgent Surgery with an urgent CT diagnosis (in first 2 hours), surgical treatment within 24 hours since the admission through the Department of Urgent Surgery with an urgent CT diagnosis (in first 2 hours) and immediate surgical treatment of ruptured AAA.

Results: In the period from Jan 1, 2005 to Dec 31, 2009, 390 patients with AAA were operatively treated. 89 patients had ruptured AAA, 52 were operated 24 hours after the urgent admission, 18 patients were operated in the first 24 hours after the urgent admission and 231 patients were planned for elective surgery. Mortality rates between the groups were asfollows: elective surgery-5.1\%, patients operated 24 hours after the urgent admission $7.2 \%$, patients operated in the first 24 hours after the urgent admission $23 \%$, and patients who had ruptured AAA $34 \%$.

Conclusion: Considering the obtained data, it can be concluded that the treatment of unruptured symptomatic AAA is related to a higher risk of postoperative mortality in relation to an elective surgery. Moreover, surgical treatment in the first 24 hours after the urgent admission of unruptured symptomatic AAA has higher rate of mortality and morbidity compared to surgical treatment 24 hours after the urgent admission of the patients, so we can conclude that the early (semi) elective surgery is a method of choice for the treatment of unruptured symptomatic AAA in acute expansion (Tab. 2, Fig. 2, Ref. 21). Full Text in PDF www.elis.sk.

Key words: abdominal aortic aneurysm, rupture, risk factors, surgical treatment.
\end{abstract}

Aneurysm is a local irreversible permanent dilatation of arterial blood vessel at least 1.5 times larger than a normal diameter of lumen of the same blood vessel (1).

Aneurysm of abdominal aorta (AAA) is the 13th cause of mortality in general, and the 10th cause of death in men older than 55 years (2). The incidence of AAA in population in the 7th decade of life is $5 \%$ for men and $1 \%$ for women (the ratio is $5: 1$ ) (3).

The decision about timing and the type of treatment of aneurysmal disease directly depends on: clinical presentation of aneurysmal disease and the relation between the risk of rupture and risk of eradication of aneurysmal disease (4).

All AAA can be divided in to two groups based on clinical presentation:

1) Asymptomatic AAA

2) Symptomatic AAA

Clinic of Vascular and Endovascular Surgery, Clinical Centre Vojvodine, Novi Sad, Serbia.

Address for correspondence: J. Pasternak, MD, PhD, Clinic of Vascular and Endovascular Surgery, Clinical Centre Vojvodine, Hajduk Veljkova 1 Novi Sad, 21000 Serbia.

Phone: +381.63.7757036, Fax: +381.21421545
Symptomatic aneurysms can be further divided in two subgroups: unruptured and ruptured.

Unruptured symptomatic AAA can be:

Aneurysm with acute symptoms caused by :

- sudden expansion of aneurysm,

- acute thrombosis and lor distal embolisation (acute peripheral ischemia)

b) Aneurysms with chronic symptoms (5).

Annual risk of rupture depends on numerous parameters and ranges from very low of about $1 \%$, over moderate of $6 \%$ to a high risk, which is sometimes over $11 \%$.

Low risk of rupture have AAA with diameter up to $44 \mathrm{~mm}$, mostly fusiformly shaped, with annual expansion below $4 \mathrm{~mm}$, while sex, heritage, smoking and hypertension do not influence this risk.

Moderate risk of rupture have AAA with diameter 45-54 $\mathrm{mm}$, saccular shape, and annual expansion of 5-9 $\mathrm{mm}$. It occurs more often in males, and heritage, smoking, and hypertension increase the risk.

High risk of rupture have AAA with diameter over $55 \mathrm{~mm}$, extremely eccentric shape, with annual expansion over $10 \mathrm{~mm}$. It occurs more often in females, while negative heritage increases 
the risk twice, and smoking, chronic obstructive lung disease and uncontrolled hypertension multiply the risk of rupture.

The level of risk for perioperative mortality is determined by following parameters: patients age, physical activity, cardiac risk, pulmonary risk, renal risk.

The risk of patient's perioperative mortality can be:
a) low (1-3\%),
b) moderate $(3-7 \%)$,
c) high $(>10 \%)$.

\section{Approach to treatment of abdominal aorta aneurysm}

Surgical approach to the treatment of AAA can be: Classical - open or endovascular.

\section{Complications of AAA surgery}

The most common complications of open surgery of AAA in perioperative period (within 30 days) can be: cardiac $15 \%$, pulmonary $12 \%$, renal $12 \%$, bleeding $<5 \%$, wound infection $<5 \%$, ischemia of extremities $<4 \%$, cerebrovascular stroke $1 \%$, ischemia of colon $<1 \%$, injury of ureter $<1 \%(6,7)$.

Perioperative morbidity also depends on whether the surgery of AAA is elective or urgent (8).

For elective surgery, accepted mortality rate should be less than $5 \%$, and the most common causes of death in these patients are cardiac $(58 \%)$, followed by pulmonary $(6 \%)$, renal $(4 \%)$, while other factors count for less than $1 \%$. At urgent surgery, the mortality risk is much higher, reaching 26-69\%, with somewhat different main causes of death. The main cause is MOF (35\%), than cardiac (20\%), bleeding (18\%), ischemia of colon and renal insufficiency $(9 \%)$, while pulmonary risk is only $6 \%$.

This mortality difference is only related to perioperative period (within 30 days of operation), while after that period risks i.e. chance for survival after open surgery for both elective and urgent aneurysmectomy of AAA equals, with 5 years survival rate of 70 $\%$, and ten years survival rate of even $40 \%$ (9).

\section{Aim of the study}

Aim of the study is:

1. definition of the entity of symptomatic unruptured abdominal aorta aneurysms,

2. the influence of timing of surgical treatment on the outcome of the treatment,

3. analysis of the results of the unruptured symptomatic (acute expansion) AAA treatment.

\section{Material and methods}

\section{Material}

Patients from Clinic for Vascular and Transplantation Surgery, Clinical Center of Vojvodina in Novi Sad, in the period from Jan 1, 2005 to Dec 31, 2009 (5 years).

\section{Methods}

Retrospective analysis of information from medical documentation (anamnesis, anesthesia records, operation charts, intensive care charts, additional clinical, radiological and laboratory documentation, hospital discharges, reports on the death) of all patients who underwent opened surgery of AAA in a 5-year period.

According to the timing of surgical treatment, all operated patients were divided into 4 groups:

- elective surgical treatment,

- surgical treatment of SYMPTOMATIC UNRUPTURED (acute expansion) AAA 24 hours after admission by The Urgent Surgery Department with urgent (within 24 hours) CT diagnosis,

- surgical treatment of SYMPTOMATIC UNRUPTURED (acute expansion) AAA within $24 \mathrm{~h}$ of admission by The Urgent Surgery Department with urgent (within 2 hours) CT diagnosis and

- immediate surgical treatment of ruptured AAA.

Each group of patients was individually analyzed according to the following parameters:

- diameter of AAA, sex and age structure,

- risk factors for AAA: smoking, hypertensive disease (HTA), diabetes mellitus (DM), cerebrovascular diseases (CVD), cardiovascular diseases (CVD),

- the choice of surgery technique (tubus or bifurcation), loss and restitution of blood in an intraoperative cell-saver device, the amount of intraoperative and postoperative blood transfusion, number of days spent in the intensive care units (ICU), number of days on respirator in ICU, early postoperative recovery, early postoperative mortality and specific morbidity.

All obtained data were statistically processed and are shown in tables for each individual group.

The choice of statistical methods was based on recommendations by Glantz (10).

As a part of descriptive statistics, following parametric characteristics were used: mean value, standard deviation, median, minimum and maximum. For non parametric characteristics, the frequency of appearance of specific categories was evaluated. Student's t-test was used in comparative statistical analysis, for evaluation of differences in mean values of attributes between the examined groups.

For comparison of the differences in intensity of occurrence between the examined groups for nonparametric attributes we used Pearson $\chi^{2}$-test, and for comparison of difference in the structure of occurrence Spearman's Rank Correlation Test.

For evaluation of inter-group differences, we used ANOVA and Student's t-test. The calculations were performed by StatSoft, Inc. package- (2007) (11).

\section{Results}

In the period from Jan 1, 2004 to Dec 31, 2008, 390 patients with diagnosed AAA were operated at Clinic for Vascular and Transplantation Surgery, Clinical Center of Vojvodina in Novi Sad.

According to the timing of surgical treatment, all patients were divided into 4 groups: 
Tab. 1. Descriptive preoperative analysis in different examined groups.

\begin{tabular}{|c|c|c|c|c|c|c|}
\hline Group & 0 & 1 & 2 & 3 & $\sum$ & $\mathrm{p}$ \\
\hline Number of patients & 231 & 52 & 18 & 89 & 390 & \\
\hline Male & 203 & 44 & 16 & 81 & 344 & 0.981 \\
\hline Average age (years) & 66.53 & 67.73 & 67.72 & 68.25 & 67.13 & 0.302 \\
\hline Maximal diameter $(\mathrm{cm})$ & 6.46 & 7.13 & 7.46 & 8.83 & 7.13 & $\mathrm{p}<0.01$ \\
\hline Hypertension & 169 & 34 & 15 & 46 & 264 & $\mathrm{p}<0.01$ \\
\hline Diabetes mellitus & 9 & 2 & 1 & 0 & 12 & 0.379 \\
\hline Cerebrovascular diseases & 31 & 9 & 2 & 3 & 45 & 0.052 \\
\hline Smoking & 171 & 38 & 14 & 40 & 263 & $\mathrm{p}<0.01$ \\
\hline Chronic obstructive pulmonary disease & 37 & 5 & 3 & 12 & 57 & 0.916 \\
\hline Peripheral arterial occlusive disease & 41 & 17 & 2 & 9 & 69 & $\mathrm{p}<0.05$ \\
\hline
\end{tabular}

Tab. 2. Intraoperative findings and postoperative characteristics of examined group of patients.

\begin{tabular}{|c|c|c|c|c|c|}
\hline Group & 0 & 1 & 2 & 3 & $\mathrm{p}$ \\
\hline Number of patients & 231 & 52 & 18 & 89 & \\
\hline Tube graft & 204 & 47 & 12 & 74 & $\mathrm{p}=0.055$ \\
\hline Number of days in Intensive Care Unit & 2.44 & 2.48 & 2.67 & 5.52 & $\mathrm{p}<0.01$ \\
\hline Number of days on respirator & 1.32 & 1.13 & 1 & 3.34 & $\mathrm{p}<0.01$ \\
\hline Average blood loss (ml) & 1263.18 & 1489.58 & 1260 & 2118.5 & $\mathrm{p}<0.01$ \\
\hline Cell saver $(\mathrm{ml})$ & 448.29 & 518.33 & 464.28 & 720.5 & $\mathrm{p}<0.01$ \\
\hline Number of hospital days & 12.13 & 13.05 & 10.83 & 17.12 & $\mathrm{p}<0.01$ \\
\hline The most common cause of death* & CMP, ARDS. & CMP, MOF & ARDS, MOF & MOF, ARDS & \\
\hline
\end{tabular}

*CMP - Cardiomyopathy, ARDS - Acute Respiratory Distress Syndrome, MOF - Multiple Organ Failure

Group 0 - comprised of 231 patients with elective surgery of AAA, and all patients underwent CT imaging which confirmed the diameter of AAA above $50 \mathrm{~cm}$.

Group 1- comprised of 52 patients who underwent surgery 24 hours after the admissionat The Department of Urgent Surgery. The admission was due to the constant intensive abdominal pain and palpable pulsatile abdominal mass at hemodynamically stable patient, with urgent (within 2 hours from admission) CT examination, which showed the diameter of AAA larger than $50 \mathrm{~cm}$, without signs of rupture.

Group 2 - comprised of 18 patients who underwent surgery within 24 hours from admission at the Department of Urgent Sur-

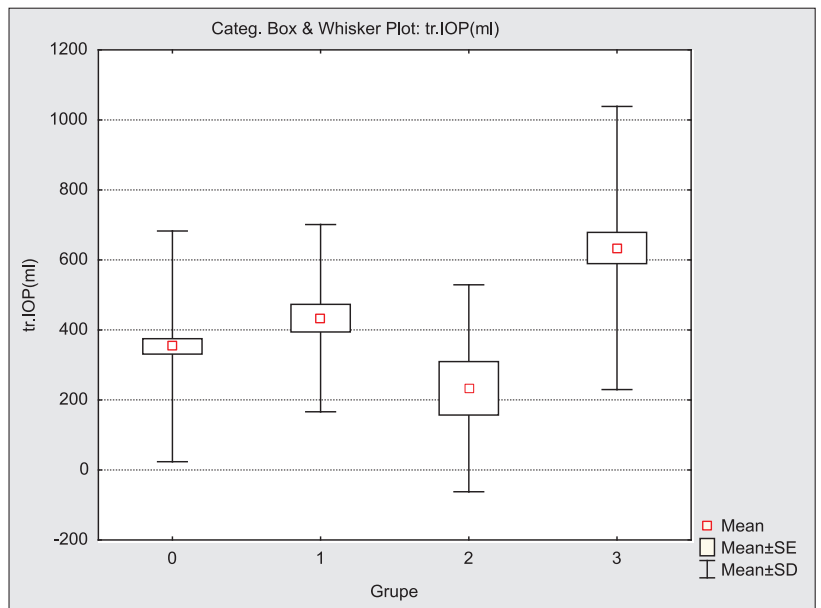

Fig. 1. Intraoperative transfusion of autologous blood. $p=0.000000$ i.e. $\mathbf{p}<\mathbf{0 . 0 5}$, thus there is statistically significant difference between groups. gery. The admission was indicated because of constant intensive abdominal pain and palpable pulsatile abdominal mass in hemodynamically stable patient, with urgent (within 2 hours) CT examination, which showed the diameter of AAA larger than $5 \mathrm{~cm}$, without signs of rupture, while indication for the urgent surgery was the progression of clinical symptoms of AAA (increased pain, peritoneal irritation, hemodynamic instability)

Group 3 - comprised of 89 patients with immediate surgical treatment of ruptured AAA.

Distribution of patients in certain examined groups in relation to basic preoperative characteristics, risk factors and comorbidity factors is shown in Table 1.

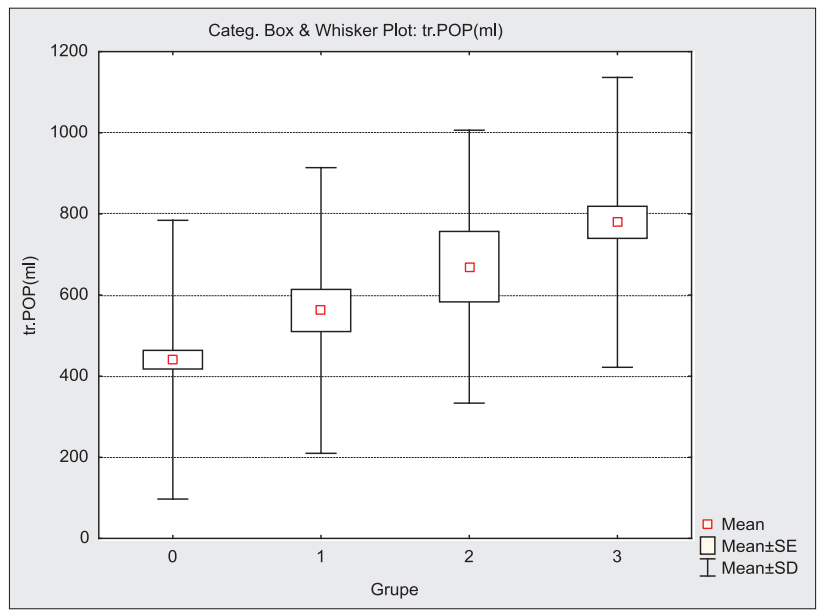

Fig. 2. Postoperative transfusion of autologous blood. $p=0.00000$ i.e. $\mathbf{p}<\mathbf{0 . 0 5}$, thus there is statistically significant difference between groups. 
Distribution of patients in examined groups in relation to the choice of surgical technique of AAA exclusion and postoperative characteristics of examined groups of patients are shown in Table 2.

The average amount of blood transfusion administered intraoperatively per patient is shown in Figure 1. The average amount of transfusion blood administered postoperatively per patient is shown in Figure 2.

\section{Discussion}

In the period from Jan 1, 2004 to Dec 31, 2008, 390 patients with diagnosed AAA were operated at Clinic for Vascular and Transplantation Surgery, Clinical Center of Vojvodina in Novi Sad.

The distribution of patients according to sex is 7.5:1 (male vs women), which is slightly above the distribution found in the literature which is 5:1 (12). Considering the age, even $79 \%$ of patients were older than 60 years, which correlates the results from literature (13).

Concerning the risk factors which influence the occurrence of AAA in all examined groups, $67 \%$ of patients are smokers, $68 \%$ have hypertension, $60 \%$ have symptomatic cardiovascular disease diagnosed prior the operation, while number of patients with DM (3 \%) and symptomatic cerebrovascular diseases diagnosed prior the operation (11\%) is much less, which correlates the references $(14,15)$.

When analyzing the influence of the diameter of aneurysm to the prognosis and symptoms, a significant difference in AAA diameter between patients planned for elective surgery and those with rupture is observed, i.e. the diameter of AAA in patients with ruptured AAA is statistically significantly larger $(\mathrm{p}<0.01)$ than in other three groups, and especially those planned for elective operation, which correlates the results in the literature $(16,17)$.

The average number of days spent in ICU in the first three groups is $2 \pm \mathrm{SD}$, while at patients with ruptured AAA it is more than 5 days, which indicates much slower postoperative recovery of patients with ruptured AAA. The average number of days on respirator in ICU in the first three groups is $1 \pm \mathrm{SD}$, while at patients with rupture it is more than 3 days, which also indicates their much slower postoperative recovery (13).

Average number of days spent in hospital in the first three groups is 10-13, while at patients with rupture of AAA it is about 17 , which indicates much better postoperative recovery of the patients from the first three groups.

The average amount of blood collected in cell-saver device in the first three groups is between $1200 \mathrm{ml}$ and $1500 \mathrm{ml}$, and 2118 $\mathrm{ml}$ at patients with ruptured AAA, while amount of blood brought back to circulation during the operation in the first three groups is between $448 \mathrm{ml}$ and $518 \mathrm{ml}$, and in patients with ruptured AAA about $720 \mathrm{ml}$, which shows that there is no significant difference in loss and restoration of blood between the first three groups, whereas that amount is significantly higher in patients with ruptured AAA.

The average amount of blood transfusion administered during the operation in the first three groups is between $233 \mathrm{ml}$ and $433 \mathrm{ml}$, while in patents with ruptured AAA is $635 \mathrm{ml}$, and amount of blood transfusion administered postoperatively in the first two groups is between $440 \mathrm{ml}$ and $560 \mathrm{ml}$, in the third group it is $670 \mathrm{ml}$, and in patients with ruptured AAA $780 \mathrm{ml}$, which indicates the benefits of patients planned for elective surgery and those with acute symptoms operated 24 hours after the admission in hospital (18).

The percentage of patients with lethal outcome in the first group is $5.1 \%$, in the second $7.2 \%$, in the third $23 \%$, while in the fourth it is as much as $34 \%$, which confirms the better outcome for the patients planned for the elective surgery and those with acute symptoms operated $24 \mathrm{~h}$ after the admission in the hospital compared to those with acute symptoms operated in less than $4 \mathrm{~h}$ after the admission, and especially those with ruptured AAA (19).

Leading cause of death in the first group is cardiomyopathy, in the second group also cardiomyopathy, while at patients in the third group the leading cause is ARDS, and in patients with ruptured AAA MODS, which as well more or less correlates the world literature $(20,21)$.

\section{Conclusion}

Surgical treatment of symptomatic unruptured AAA in expansion is related to increased risk of perioperative mortality and morbidity.

Urgent surgery of AAA is related to high perioperative mortality and morbidity.

The term symptomatic unruptured aneurysm in expansion means aneurysmatic dilatation of abdominal aorta in hemodynamically stable patient with intensive constant abdominal pain and CT examination which excludes the rupture of abdominal aorta aneurysm.

Early elective surgery is the method of choice in the treatment of symptomatic unruptured AAA in expansion.

\section{References}

1. Sonesson B, Lanne T, Hansen F, Sandgren T. Infrarenal aortic diameter in the healthy person. Eur J Vasc Surg 1994; 8: 89-95.

2. Choke E, Cockerill G, Wilson WRW, Sayed S, Dawson J, Loftus I, Thompson MM. A Review of Biological Factors Implicated in Abdominal Aortic Aneurysm Rupture. Eur J Vasc Endovasc Surg 2005; 30: 227-244.

3. Zarins CK, Xu C, Glagov S. Atherosclerotic enlargement of the human abdominal aorta. Atherosclerosis 2001; 155 (1): 157-164.

4. Lee ES, Pickett E, Hedayati N, Dawson DL, Pevec WC. Implementation of an aortic screening program in clinical practice. J Vasc Surg 2009; 49: 1107-1111.

5. Shnacker A; Witz M; Lehmann JM. Acute thrombosis of an aortic aneurysm. J Cardiovasc Surg (Torino) 2001; 42 (1): 111-113.

6. Menard MT, Chew DK, Chan RK, Conte MS, Donaldson MC, Mannick JA, Whittemore AD, Belkin M.Outcome in patients at high risk after open surgical repair of abdominal aortic aneurysm. J Vasc Surg 2003; 37 (2): 285-292.

7. Nesi F, Leo E, Biancari F, Bartolucci R, Rainio P, Satta J, Rabitti G, Juvonen T. Preoperative risk stratification in patients undergoing elective infrarenal aortic aneurysm surgery: evaluation of five risk scoring methods. Eur J Vasc Endovasc Surg 2004; 28 (1): 52-58. 
$652-656$

8. Lewis DR, Bolton JF, Hebard S, Smith FC, Baird RN,Lamont PM. Risk factor documentation in elective and emergency vascular surgical admissions. Eur J Vasc Endovasc Surg 2003; 25: 568-572.

9. Brewster DC, Cronenwett JL, Hallett JW Jr, Johnston KW, Krupski WC, Matsumura JS. Guidelines for the treatment of abdominal aortic aneurysms: report of a subcommittee of the Joint Council of the American Association for Vascular Surgery and Society for Vascular Surgery. J Vasc Surg 2003; 37: 1106-1117.

10. Glantz, Stanton A. Primer of biostatistics. 5th ed. New York: McGraw-Hill, Medical Pub. Div., 2002.

\section{1. http://www.statsoft.com/}

12. Dueck AD, Johnston KW, Alter D, Laupacis A, Kucey DS. Predictors of repair and effect of gender on treatment of ruptured abdominal aortic aneurysm. J Vasc Surg 2004; 39: 784-787.

13. Nackman GB, Banavage A, Graham AM et al. Predictors of health after operation for aortoilliac occlusive and aneurismal disease. Surgery 2001; 130: 370-377.

14. The UK Small Aneurysm Trial Participants. The long-term prognosis of patients with small abdominal aortic aneurysms following surgery or surveillance: 12-year final follow-up of patients enrolled in the UK Small Aneurysm Trial. Br J Surg 2007; 94: 709-716.

15. Hatori N, Yoshizu H, Shimizu M, Hinokiyama K, Takeshima S, Kimura T, Iizuka Y, Tanaka $\mathbf{S}$ et al. Prognostic factors in the surgical treatment of ruptured abdominal aortic aneurysms. Surg Today 2000: 30: $785-790$
16. Sukhija R, Aronow WS, Sandhu R, Kakar P, Babu S. Mortality and size of abdominal aortic aneurysm at long-term follow-up of patients not treated surgically and treated with and without statins. Am J Cardiol 2006; 97: 279-280.

17. Hirsch AT, Haskal ZJ, Hertzer NR, Bakal CW, Creager MA, Halperin JL, Heratzka LF, Murphy WRC, Olin JW, Puschett JB, Rosenfield KA, Sacks D, Stanley JC, Taylor LM Jr, White CJ, White J, White RA. ACC/AHA guidelines for the management of patients with peripheral arterial disease (lower extremity, renal, mesenteric, and abdominal aortic). J Am Coll Cardiol 2006; 47: 1239-1312.

18. Hallin A, Bergqvist D, Holmberg L. Literature review of surgical management of abdominal aortic aneurysm. Eur J Vasc Endovasc Surg 2001; 22 (3): 197-204.

19. Wanhainen A, Bergqvist D, Boman K, Nilsson TK, Rutegard J, Björck M. Risk factors associated with abdominal aortic aneurysm: a population-based study with historical and current data. J Vasc Surg 2005; 41 (3): 390-396.

20. Cambria RA, Gloviczki P, Stanson AW, Cherry Jr KJ, Hallett Jr JW, Bower TC et al. Symptomatic, nonruptured abdominalaortic ameurysms: are emergent operations necessary? Ann Vasc Surg 1994; 8: $121-126$

21. Malina M, Nilsson M, Ivancev K, Resch T, Lindbald B et al. Quality of life before and after endovascular and open repair of asymptomatic AAA: a prospective study. J Endovasc Ther 2000: 7: 372-379.

Received June 6, 2011. Accepted August 18, 2012. 